\title{
LATE ABSTRACTS
}

Acta Cryst. (2005). A61, C498

Structure of a PACE Protein: PAB0955, First Member of new

GTPase Family.

$\underline{\text { Stéphanie Gras }}^{\mathrm{a}^{*}}$, Bernard Fernandez ${ }^{\mathrm{b}}$, Valérie Chaumont ${ }^{\mathrm{b}}$, Philippe Carpentier $^{\mathrm{a}}$, Jean Armengaud ${ }^{\mathrm{b}}$, Dominique Housset ${ }^{\mathrm{a}} .{ }^{a} I B S$ J.-P. Ebel, CEA-CNRS-UJF, Grenoble, France, ${ }^{b} S B T N$, CEA-Valrho, Bagnols sur Céze, France. E-mail: stephanie.gras@ibs.fr

PACE proteins are Proteins from Archaea Conserved in Eukarya and not found in Bacteria [1]. These proteins are likely to be involved in vital function like cellular cycle, transcription or DNA repair. Our goal was to figure out whether the knowledge of the 3D structure may help to unveil the biological function of these proteins [2]. The PAB0955 gene, of Pyroccocus Abyssi is located between the MCM gene (an essential helicase for replication initiation) and the gene of a MinD like protein (control of cellular division). One of the three humans homologues of PAB0955, XAB1, is known to interact with XPA (protein involved in DNA repair [3]). We have solved the crystal structure of PAB0955 in its apo form as well as in complex with different nucleotides and ions. PAB0955 is homodimer of $60 \mathrm{kDa}$, with a Rossmann fold topology and a phosphate binding loop (P-loop) close to the N-terminus. All together, these structures have supplied us with a few snapshots of the GTP hydrolysis mechanism. The structural analysis of all these structures allowed to identified PAB0955 as a the member new GTPase family. This family had several structural particularities, conserved in Archaea and in Eukarya and two specifics motifs in all the PACE12 amino acids sequence.

[1] O-Matte-Tailliez, Y.Zivanovic, P.Forterre, Trends in Genetics, 2000, 16, 533. [2] www-archbac.u-psud.fr [3] Nitta M, Saijo M, Kodo N, et al. Nucl Acids Res, 2000, 28, 4212

Keywords: GTPase, P-loop, kinase

P.30.01.10

Acta Cryst. (2005). A61, C498

Cross- and Alloreactivity, MHC Restriction: Lessons from TCRpMHC Structures.

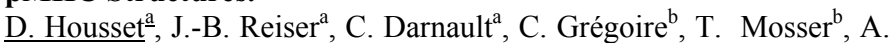
Guimezanes $^{\mathrm{b}}$, A.-M. Schmitt-Verhulst ${ }^{\mathrm{b}}$, J.C. Fontecilla-Camps ${ }^{\mathrm{a}}$, G. Mazza $^{\mathrm{b}}$, B. Malissen ${ }^{\mathrm{b}}$ a IBS J.-P. Ebel, CEA-CNRS-UJF, Grenoble, France. ${ }^{b}$ CIML, INSERM-CNRS, Marseille, France. E-mail: hous007@ibs.fr

The $\mathrm{T}$ lymphocytes protect the organism against pathogens internalized by cells such as viruses or bacteria and against some kinds of cancer. To achieve this goal, T cells display Ig-like receptors (TCRs) capable of distinguishing self- and non-self protein fragments when bound to Major Histocompatibility Complex (MHC) molecules present on the surface of antigen presenting cells. Since 1996, 19 TCR-pMHC structures have been determined in different laboratories, among which is ours[1,2], allowing very significant advances in our understanding of TCR recognition. We will focus on the structural basis of three key features: (1) $\mathrm{T}$ cell crossreactivity for several antigens, that makes the $T$ cell repertoire more efficient but also lead to autoimmune diseases. (2) T cell alloreactivity (ability of being activated by intraspecies allelic variants of self-MHC molecules), property responsible for graft rejection and graft-versus-host disease. (3) MHC restriction, or the incidence of the set of MHC molecules (haplotype) on the presented peptides and the selected $\mathrm{T}$ cell repertoire.

[1] Reiser, J.B., Darnault, C., Grégoire, C., Mosser, T., Mazza, G., Kearney, A., van der Merwe, P.A., Fontecilla-Camps, J.C., Housset, D. and Malissen, B. (2003) Nature Immunology, 4, 241-247. [2] Housset, D. and Malissen, B.

(2003) Trends Immunol., 24, 429-437.

Keywords: TCR, alloreactivity, crossreactivity 